other specific metric. Second, numerical methods have progressed to the point where they can handle, for instance, the initial stages of relativistic collapse of a magnetized star (K. Maeda, Institute of Fundamental Physics, Kyoto). These algebraic and numerical methods are still regarded with some scepticism by the majority of relativists. L. Smarr (University of Illinois at Urbana-Champaign) spoke feel- ingly of the need for collaboration between the small groups working with these approximation methods and the main body of relativists with their enormous skills at finding and understanding exact analytical solutions. To which, amen.

Virginia Trimble is Visiting Professor of Astronomy, University of Maryland, College Park, Maryland 20742, on leave from the University of California, Irvine.

\title{
Population
}

\section{Nations and numbers, 1983}

\section{from Robert M. May}

THE United Nations Fund for Population Activities is supported by voluntary contributions from member nations, and provides information and technical aid to countries operating programmes of family planning. According to a report recently issued by the Fund (16 June 1983), the number of people in the world is expected to increase annually at a rate of about 2.0 per cent over the period 1980-1985, which represents a significant downturn from the 2.4 per cent annual rate that prevailed in 1965-1970. Gazing to the future, through glasses that in the past have usually proved rose-tinted, the Fund suggests a continuing slowing of population growth throughout the next century, with eventual stability at a global population of slightly over $10^{10}$ at the end of the twenty-first century; the present global population is around $4.6 \times 10^{9}$.

As reviewed in previous articles (Nature 287,$482 ; 1980$ and 271,$504 ; 1978$ ), there are great differences - both at present and in the probable future - between population trends in the developed and the developing (or, less euphemistically, the rich and the poor) countries. According to the United Nations Fund report, smaller families and fewer births are the key to a population's levelling off. In the industrial nations, the average annual birth rate has held roughly steady at around 16 per 1,000 of population over the past decade. In the Third World, annual birth rates are now about 33 per 1,000; this is significantly down from an average of around 37 per 1,000 in the years $1970-1975$, but there is a long way to go.

The report acknowledges that overall population growth rates appear to be outrunning increases in food production in developing countries, and estimates that by the end of this century such countries may have in excess of 400 million more people than they can feed. The report envisages that this problem will yield to a technological solution (use of more fertilizer, more pesticide and higher-yielding strains of crops in developing countries), although I think higher levels of import from developed countries is a more plausible hope.

Four in every ten of the world's people live in China or India today. These two populations - approximately 1,000 million in China and 700 million in India are in a class by themselves; the next largest populations are those of the USSR and the USA, each roughly one-third that of India. Coale's (Proc. natn. Acad. Sci. U.S.A. 80, $1757 ; 1983$ ) careful evaluation of the demographic facts for these two countries is therefore especially pertinent to any appraisal of global trends.

At the outset, Coale emphasizes that "Data on population in China and India in the past 30 years are characterized by different kinds of limitation and uncertainty"'. For India, where 12 censuses have been carried out since 1872 , extensive compilations of data are available, but they are

Estimated average annual birth and death rates per 1,000 in China and India

\begin{tabular}{ccc} 
& China & \multicolumn{2}{c}{ India } \\
Decade & Births Deaths Births Deaths
\end{tabular}

$\begin{array}{rrrrr}1950 \mathrm{~s} & 36 & 18 & 45 & 26 \\ 1960 \mathrm{~s} & 36 & 13 & 41 & 19 \\ 1970 \mathrm{~s} & 23 & 7 & 39 & 17\end{array}$

inaccurate: ages are often grossly misreported, and births and deaths not always registered. In contrast, for China the record-keeping associated with pervasive government control of daily life and the precision about birth dates associated with traditional beliefs in astrology make the possibility of obtaining accurate data "tantalizingly present"; but little attention has been given to compiling these data.

These caveats having been made, Coale presents estimates of the average annual birth and death rates in the two countries, decade by decade, over the $\mathbf{3 0}$ years that have passed since their emergence from largely colonial status at the end of World War II. These data are summarized in the table. We see that the average annual rate of population growth in the 1950s was slightly larger in India than in China (about 19 per 1,000 , or 1.9 per cent, compared with 1.8 per cent), whereas in the 1960 s the reverse was true (2.3 per cent in China compared with 2.2 per cent in India). In the 1970 s, however, the average annual population growth rate in China fell to about 1.6 per cent, while remaining 2.2 per cent in India.

Although the two countries are similar in that both are relatively poor and heavily agricultural (in both, 80 per cent of the people live in the country), there are pronounced differences in birth and death rates; these tend to be obscured by the similarities in overall population growth rates. Coale attributes the lower and more improved death rate in China to two main factors. First, the relatively egalitarian distribution of income in China has meant that although "per capita availability of food is only moderately more favorable, those at the bottom of the scale are less deprived in China than in India". Second, the number of physicians per person is roughly three times larger in China than in India, and this relative abundance of physicians is also better distributed (in India, the doctor/patient ratio is eight times higher in cities than in the countryside). As important, Chinese health care is supplemented by paramedical personnel or 'barefoot doctors', and by strong emphasis on preventive medicine (including clean water supplies and the fly-swatter-implemented 'campaign against flies').

The table also shows the dramatic decline in the Chinese birth rate in the 1970s, undoubtedly associated with such centralized coercion as the requirement that couples obtain a 'planned birth certificate' before the wife becomes pregnant. In India, Coale notes, "Despite official support (for 30 years) of family planning, the government of India has not been able to organize a birth control program that regularly provides adequately staffed services to most of the population". In the mid-1970s, attempts at coercive measures not too different in principle from those implemented in China led to the fall of the Ghandi government.

In summary, Coale estimates that if present trends are sustained the population of China may stabilize at about 1,200 million by the year 2020 ; this represents a 75 per cent increase from the 700 million people present when the birth rate began its dramatic decline in the mid-1960s. India today has demographic parameters rather similar to China in the mid-1960s, and Coale thus estimates that even if fertility in India starts to fall soon the population is unlikely to stabilize below 1,200 million. In short, the two largest populations in the world are fated to become much larger.

In conclusion, Coale emphasizes that "A lower birth rate now is desirable, but the ideal rate is not zero. There are social and political costs of excessive emphasis on the immediate achievement of very small families; the rights and sensibilities of the current population, and the disequilibrating effects of drastic changes in age composition must enter the calculation of desirable population policies".

Robert M. May is Class of 1877 Professor of Zoology at Princeton University, New Jersey 08544. 